\title{
MATERIAŁY DO POZNANIA MACROMYCETES REZERWATU PRZYRODY „SWIDWIE” (NW POLSKA)
}

\author{
MAŁGORZATA STASIŃSKA, ZOFIA SOTEK \\ Instytut Nauk o Morzu i Środowisku, Uniwersytet Szczeciński, \\ ul. Adama Mickiewicza 16, 70-383 Szczecin, \\ ORCID 000-0001-9367-9275 (MS), ORCID 0000-0002-8303-9044 (ZS)
}

\begin{abstract}
The paper presents the results of mycological research carried out in "Świdwie" nature reserve (NW Poland) in 2018. 117 fungal species were identified: 15 Ascomycota and 102 Basidiomycota. Five of the recorded species have been included in the Polish red list of macrofungi, e.g. Fistulina hepatica, Mycena belliarum and Porodaedalea pini.
\end{abstract}

Keywords: macrofungi, endangered species, West Pomerania, Poland

\section{WSTĘP}

Rezerwat przyrody „Świdwie”, o powierzchni 904,04 ha, jest położony w północno-zachodniej Polsce, na południowym skraju Puszczy Wkrzańskiej, około $20 \mathrm{~km}$ na zachód od Polic i około $23 \mathrm{~km}$ od centrum Szczecina. Jest rezerwatem unikatowym w skali europejskiej, chroniącym ptactwo wodne i błotne. Został utworzony w 1963 r. (Zarządzenie..., 1963). Obejmuje jezioro Świdwie i tereny wokół niego (szuwary, bagna i torfowiska niskie). Obszar rezerwatu charakteryzuje się dużym zróżnicowaniem roślinności. Dominują tam zbiorowiska wodne i szuwarowe. Znaczne powierzchnie, głównie na obrzeżach, zajmują zbiorowiska zaroślowe i leśne (ryc. 1). Występują tam m.in. wilgotne lasy łęgowe Fraxino-Alnetum i bagienne lasy olszowe Ribeso nigri-Alnetum (ryc. 2), często niedostępne ze względu na okresowe podtopienia, oraz lasy z dominacją w drzewostanie brzozy, sosny i buka, niekiedy z domieszką świerka i dębu, często trudne do klasyfikacji fitosocjologicznej (Bosiacka i in. 2013/2014).

Biota grzybów makroskopijnych rezerwatu „Świdwie” nie była dotychczas w dostatecznym stopniu poznana. Tylko dwa gatunki, tj. Calvatia gigantea i Mycena belliarum, zostały ujęte w pracy Friedricha (2006), który prowadził badania mykologiczne w Puszczy Wkrzańskiej. W latach 2009-2010 wstępne obserwacje grzybów makroskopijnych wykonywały Bosiacka i Więcław (2013/2014), podając $\mathrm{z}$ tego obszaru, głównie $\mathrm{z}$ terenów leśnych, 110 gatunków grzybów makroskopijnych. Podczas prac związanych z przygotowaniem operatu do planu 


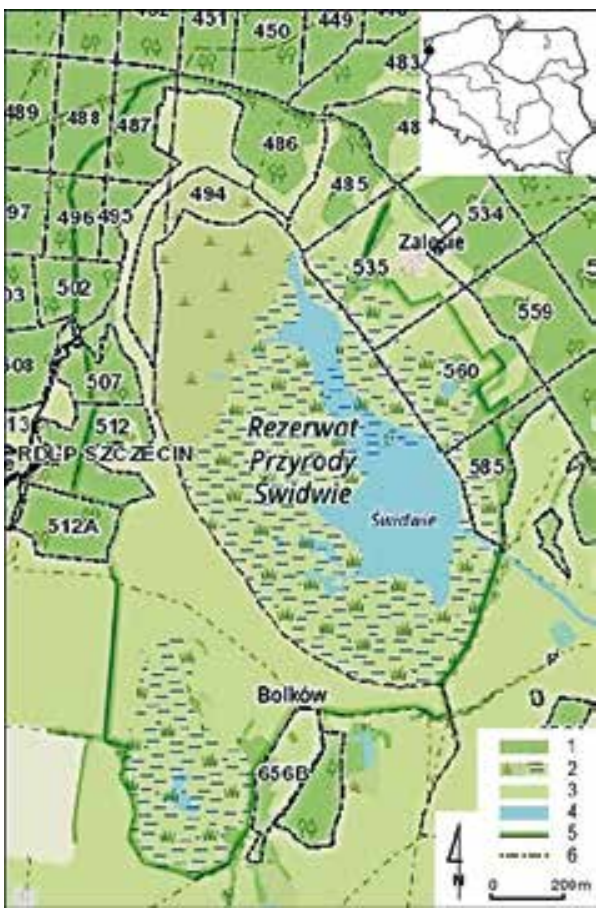

Ryc. 1. Lokalizacja i mapka rezerwatu przyrody „Świdwie” (źródło: Bank Danych o Lasach, https://www.bdl.lasy.gov.pl/portal/ mapy, zmienione)

1 - lasy, 2 - roślinność bagienna, 3 - łąki,

4 - wody, 5 - granica rezerwatu, 6 - drogi

Fig. 1. Locality and map of the „Świdwie” nature reserve (source: Bank Danych o Lasach, https://www.bdl.lasy.gov.pl/portal/ mapy, modified)

1 - forests, 2 - marsh vegetation, 3 - meadows, 4 -water bodies, 5 - border of reserve,

$$
6 \text { - roads }
$$

ochrony rezerwatu autorki niniejszej pracy prowadziły obserwacje mykologiczne, których wyniki obecnie prezentują. Stanowią one przyczynek do pełniejszego poznania słabo jeszcze rozpoznanej mycobioty rezerwatu.

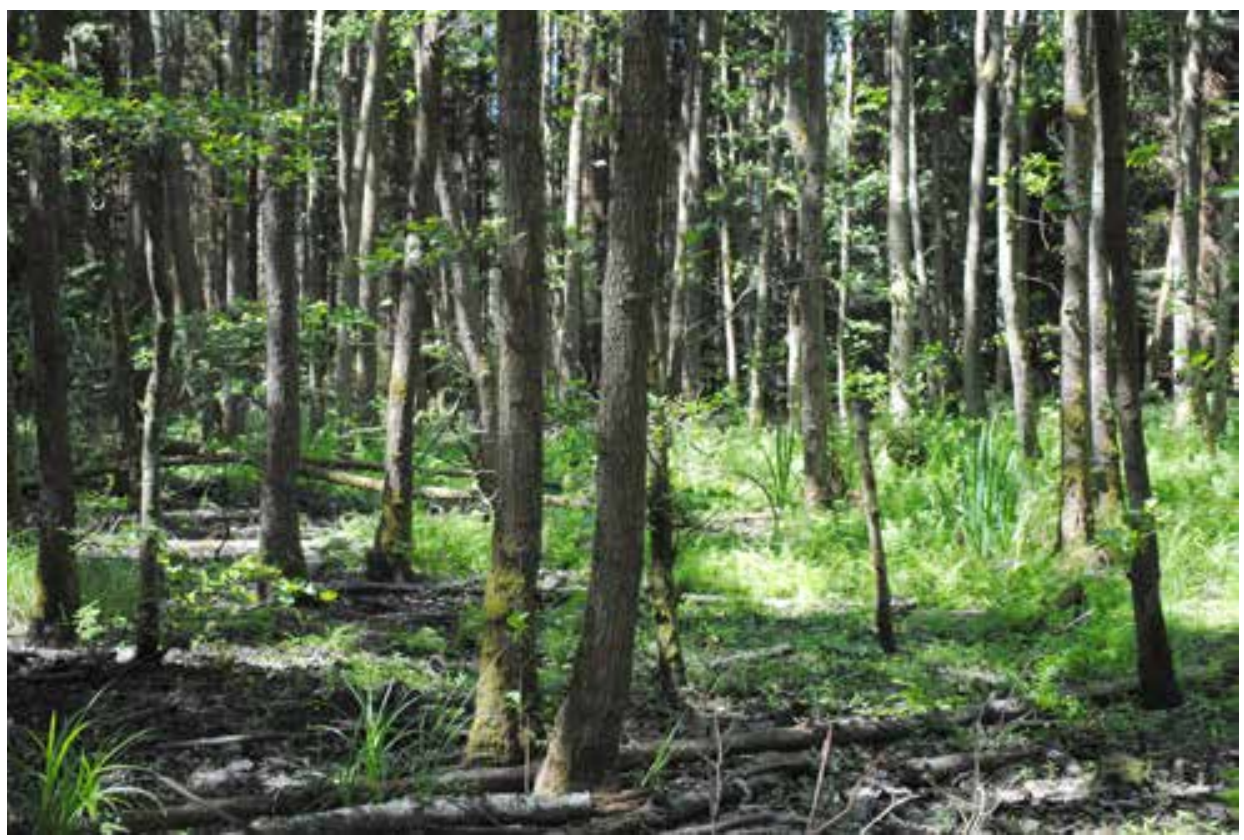

Ryc. 2. Olszyna bagienna w rezerwacie przyrody „Świdwie”. Fot. M. Stasińska Fig. 2. Boggy alder ferest in the „Świdwie” nature reserve. Phot. M. Stasińska 


\section{Podziękowanie}

Autorki składają serdeczne podziękowania Panu Kazimierzowi Olszanowskiemu za przekazanie informacji o stanowiskach Mycena belliarum oraz Panu Tomaszowi Rekowi za przekazanie danych o kilku gatunkach grzybów występujących w rezerwacie „Świdwie”.

\section{METODY BADAŃ}

Badania terenowe na obszarze rezerwatu „Świdwie” w zakresie bioty grzybów wielkoowocnikowych prowadzono metodą marszrutową, od maja do września 2018 r. W przypadku stwierdzenia stanowisk rzadkich w skali regionu i Polski, zagrożonych i chronionych gatunków grzybów makroskopijnych odnotowano miejsca ich występowania i określono (za pomocą GPS) współrzędne geograficzne tych stanowisk.

Nazewnictwo grzybów wielkoowocnikowych przyjęto za MycoBank (Robert et al. 2005) i Index Fungorum (2019). Nazwy roślin naczyniowych podano za Mirkiem i in. (2002), a nazewnictwo zbiorowisk roślinnych za Matuszkiewiczem (2001).

Wyniki badań przedstawiono w postaci listy gatunków w układzie alfabetycznym, oddzielnie dla Ascomycota i Basidiomycota. Dla każdego gatunku podano: typ podłoża, na którym występował, oddział leśny, w którym został stwierdzony, oraz okres występowania (miesiące i rok). Dla stanowisk wybranych gatunków podano także ich położenie według GPS. Kategorie zagrożenia grzybów podano za Wojewodą i Ławrynowicz (2006), a status prawny według Rozporządzenia Ministra Środowiska... (2014). Zebrane eksykaty złożono w zielniku Uniwersytetu Szczecińskiego (SZUB-F).

Przyjęte skróty: oddz. - oddział leśny; V-IX 2018 - okres występowania; $\mathbf{C h}$ - gatunki objęte ochroną częściową; kategorie zagrożenia: $\mathbf{E}$ - wymierające, $\mathbf{R}$ - rzadkie.

\section{WYNIKI}

W rezultacie przeprowadzonych badań na terenie rezerwatu „Świdwie” stwierdzono łącznie 117 gatunków grzybów makroskopijnych, w tym 15 przedstawicieli Ascomycota i 102 Basidiomycota. Wśród odnotowanych taksonów pięć znajduje się na czerwonej liście grzybów wielkoowocnikowych w Polsce (Wojewoda, Ławrynowicz 2006). Do najwyższej kategorii E (wymierających) należy Mycena belliarum, do kategorii R (rzadkich) klasyfikowane są: Inonotus obliquus, Fistulina hepatica, Polyporus tuberaster i Porodaedalea pini, przy czym dwa pierwsze podlegają jednocześnie ochronie częściowej (Rozporządzenie..., 2014).

Spośród gatunków zagrożonych najliczniej i najczęściej notowano Porodaedalea pini. Na pojedynczych stanowiskach stwierdzone zostały: Fistulina he- 
patica, Inonotus obliquus i Polyporus tuberaster. Do gatunków notowanych od wielu lat, w kilku miejscach, w trzcinach otaczających jezioro Świdwie, należy grzybówka trzcinowa Mycena belliarum (informacja ustna, K. Olszanowski). Jest to grzyb rzadki nie tylko w skali Pomorza, ale także w skali całego kraju, natomiast pozostałe gatunki były notowane znacznie częściej (Wojewoda 2003).

Z analizy bioty grzybów makroskopijnych odnotowanych na obszarze rezerwatu wynika, że większość z nich to gatunki o szerokiej skali ekologicznej, spotykane w różnego typu fitocenozach leśnych i zaroślowych. Do tej grupy należą grzyby nadrewnowe, które zdecydowanie dominowały ze względu na panujące niekorzystne dla rozwoju grzybów z innych grup ekologicznych warunki klimatyczne (wysokie temperatury i mała ilość opadów). Na żywych i martwych pniach brzóz oraz innych drzew liściastych rosły m.in.: Fomes fomentarius, Piptoporus betulinus i Daedaleopsis confragosa, a na drobnych gałązkach i gałęziach m.in.: Diatrype stigma, Diatrypella verrucaeformis i Exidia plana. Na jeszcze żywych pniach ponad 100-letnich sosen stwierdzono występowanie Porodaedalea pini, natomiast na martwych kłodach, pniakach i gałęziach Pinus sylvestris rosły m.in.: Fomitopsis pinicola, Stereum sanguinolentum, Trichaptum abietinum i T. hollii. Na martwych pniach i gałęziach dębu owocniki wykształcały m.in.: Diatrypella quercina, Peniophora quercina, Polyporus badius, Vuilleminia comedens i Xylodon paradoxus. Drewno bukowe zasiedlane było m.in. przez Diatrype disciformis i Hypoxylon fragiforme. Sporadycznie pojawiały się grzyby rosnące na ziemi, m.in.: Amanita fulva, A. rubescens, Russula cyanoxantha i Xerocomellus cisalpinus.

\section{WYKAZ GATUNKÓW GRZYBÓW}

\section{Ascomycota}

Bertia moriformis (Tode) de Not. - na martwych gałązkach; oddz. 486c, 488g; V-IX 2018.

Colpoma quercinum (Pers.) Wallr. - na martwych gałązkach Quercus; oddz. 485a, b, 486f, 502c; V 2018.

Dialonectria episphaeria (Tode) Cooke [=Nectria epishaeria (Tode) Fr.] - na podkładkach Diatrype stigma; oddz. 486c, f; V-IX 2018.

Diatrype disciformis (Hoffm.) Fr. - na martwych gałązkach i gałęziach Fagus; oddz. 486c, d, 487h, k, 488g, 496a; V-IX 2018.

D. stigma (Hoffm.) Fr. - na martwych gałązkach i gałęziach Betula; oddz. 485a, 486c, d, f, 487h, 488g, 502c, 507a, b, 512d; V-IX 2018.

Diatrypella quercina (Pers.) Cooke - na martwych gałązkach i gałęziach Quercus; oddz. 485b, 486d, f, 487h, k, 488g, 507a, b, 512d; V-IX 2018. 
Diatrypella verrucaeformis (Ehrh.) Nitschke - na martwych gałązkach i gałęziach Betula; oddz. 485b, 486c, f, 487h, k, 488g, 495b, f, 496a, c, 502c, 512b, c, d; V-IX 2018.

Hypoxylon fragiforme (Pers.) J. Kickx f. - na martwych gałęziach Fagus; oddz. 486c, d, f, 487h, k, 488g, 496a, 502c, 507a, b; V-IX 2018.

Jackrogersella multiformis (Fr.) L. Wendt, Kuhnert \& M. Stadler [=Hypoxylon multiforme (Fr.) Fr.] - na martwych gałęziach Betula; oddz. 485a, b, 496a; V-IX 2018.

Kretzschmaria deusta (Hoffm.) P.M.D. Martin [=Ustulina deusta (Hoffm.) Maire] - na pniakach Fagus; oddz. 485a, 486f, 487h, 488g; V-IX 2018.

Mollisia cinerea (Batsch) P. Karst. - na martwym drewnie; oddz. 485d, 486c; VIII 2018.

Scutellinia scutellata (L.) Lambotte - na murszejących gałęziach Betula; oddz. 485d, 486f; VIII 2018.

Xylaria carpophila (Pers.) Fr. - na martwych kupulach Fagus; oddz. 487h, 488g; VII-IX 2018.

X. hypoxylon (L.) Grev. - na martwych pniakach; oddz. 486c, d, 487h; V-IX 2018.

X. longipes Nitschke - na martwym drewnie, oddz. 485a; VIII 2018.

\section{Basidiomycota}

Amanita citrina (Schaeff.) Pers. - na ziemi; oddz. 485d, 488g; IX 2018.

A. fulva Pers. - na ziemi; oddz. 485d, 488g; VI-VIII 2018.

A. rubescens Pers. - na ziemi; oddz. 485a; VII-VIII 2018.

Auricularia auricula-judae (Bull.) J. Schröt. - na kłodach Fagus; oddz. 485a; VIII-IX 2018.

Auriscalpium vulgare Gray - na szyszkach Pinus; oddz. 485a, 486c, d; V-IX 2018.

Baeospora myosura (Fr.) Singer - na szyszkach Pinus; oddz. 485a; IX 2018.

Bjerkandera adusta (Willd.) P. Karst. - na martwych pniakach i pniach; oddz. 486c, d; V-IX 2018.

Calocera cornea (Batsch) Fr. - na martwej gałęzi; oddz. 488; IX 2018.

C. viscosa (Pers.) Fr. - na pniakach Pinus; oddz. 485a; VIII-IX 2018.

Calvatia utriformis (Bull.) Jaap - na ziemi; oddz. 502g, przy drodze do Bolkowa; VII-IX 2018.

Chlorophyllum rhacodes (Vittad.) Vellinga [=Macrolepiota rhacodes (Vittad.) Singer var. rhacodes] - na ziemi; oddz. 485d; IX 2018.

Chondrostereum purpureum (Pers.) Pouzar - na kłodzie; oddz. 486d; VI-IX 2018.

Coniophora arida (Fr.) P. Karst. - na martwych gałęziach iglastych; oddz. 485a, 487h, k; V-IX 2018. 
Coprinellus micaceus (Bull.) Vilgalys, Hopple \& Jacq. Johnson [=Coprinus micaceus (Bull.) Fr.] - na pniaku; oddz. 485a; IX 2018.

Dacrymyces stillatus Nees - na martwych gałęziach, kłodach, pniakach i pniach; oddz. 485a; VIII-IX 2018.

Daedaleopsis confragosa (Bolton) J. Schröt. - na martwych pniach Betula; oddz. 486c, d, f, 495b, f, 496c; V-IX 2018.

Datronia mollis (Sommerf.) Donk - na martwym pniu; oddz. 485b; V-IX 2018.

Exidia pithya (Alb. \& Schwein.) Fr. - na martwej kłodzie iglastej; oddz. 485a, 507a; VII-IX 2018.

Exidia plana Donk - na martwych gałązkach, gałęziach i kłodach; oddz. 485a, b, 486c, d, 487h, 488g, 507a, b, 512d; VII-IX 2018.

Fistulina hepatica (Schaeff.) With. - u podstawy pnia Quercus; oddz. 484f (N $53^{\circ} 34^{\prime} 774, \mathrm{E} 14^{\circ} 22^{\prime}$ ' 188); przy drodze leśnej w sąsiedztwie oddz. 485a; VII-VIII 2018. R, Ch (ryc. 3).

Fomes fomentarius (L.) Fr. - na gałęziach, kłodach i pniach drzew liściastych, np. Betula, Fagus; oddz. 485a, d, 486c, d, 487h, k, 488g, 494a, b, c, 495a, 496a, 507a, b; V-IX 2018.

Fomitopsis pinicola (Sw.) P. Karst. - na kłodach i martwych pniach Pinus; oddz. 487h, k, 488g, 494b, c, 496a, 507a, b; V-IX 2018.

Galerina marginata (Batsch) Kühner - na martwej kłodzie iglastej; oddz. 487h; VII 2018.

Ganoderma lipsiense (Batsch) G.F. Atk. - na pniakach i kłodach Fagus; oddz. 485a, b, 486f, 507a, b, 512d; V-IX 2018.

Gymnopus androsaceus (L.) J.L. Mata \& R.H. Petersen - na igłach; oddz. 485a, 488g; VIII-IX 2018.

G. confluens (Pers.) Antonín, Halling \& Noordel. - na ściółce; oddz. 488g; VIII 2018.

G. dryophilus (Bull.) Murrill - na ściółce; oddz. 485a, 488g; VII-IX 2018.

G. peronatus (Bolton) Gray - na ściółce iglastej i liściastej; oddz. 485a, 488g; VII-IX 2018.
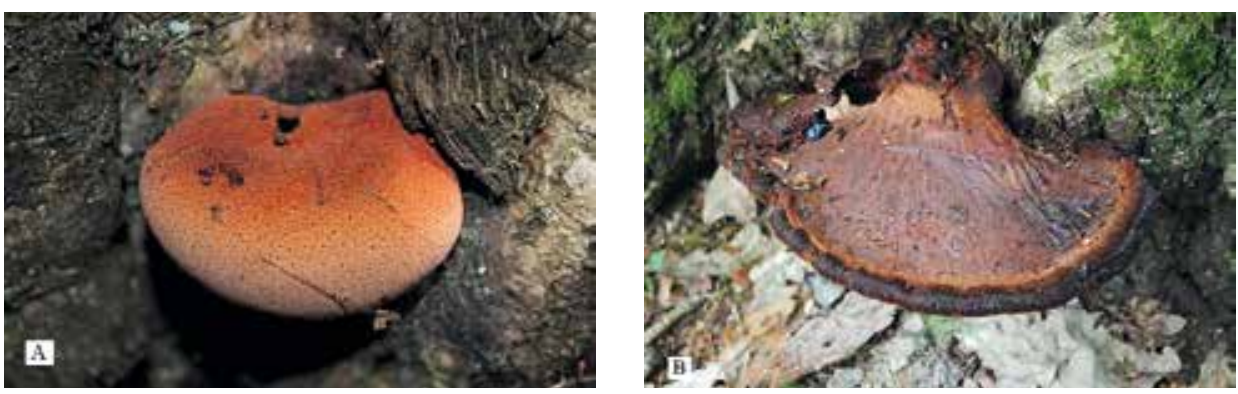

Ryc. 3. Fistulina hepatica: A - młody owocnik, B - stary owocnik. Fot. M. Stasińska Fig. 3. Fistulina hepatica: A - young fruit-body, B - old fruit-body. Phot. M. Stasińska 
Hapalopilus nidulans (Fr.) P. Karst. - na gałęzi Quercus; oddz. 485a; VIII 2018. Heterobasidion annosum (Fr.) Bref. - na pniaku Pinus; oddz. 485a, d, 486c; VII-VIII 2018.

Hymenochaete rubiginosa (Dicks.) Lév. - na pniaku Quercus; oddz. 485a, 507a; V-IX 2018.

Hymenopellis radicata (Relhan) R.H. Petersen [=Xerula radicata (Relh.) Dörfelt] - na korzeniach Fagus; oddz. 486c; VIII 2018.

Hyphoderma setigerum (Fr.) Donk - na martwych gałęziach; oddz. 487h; VII 2018.

Hypholoma fasciculare (Huds.) P. Kumm. - na pniakach i u podstawy pni drzew; oddz. 485a, 487h, k; VII-IX 2018.

Inonotus nodulosus (Fr.) P. Karst. - na martwej kłodzie; oddz. 488g; V-IX 2018.

Inonotus obliquus (Ach. ex Pers.) Pilát - na żywym pniu Betula; oddz. 496a (N 53 34' 645, E 14 20' 708); V-IX 2018. R, Ch (ryc. 4).

Kuehneromyces mutabilis (Schaeff.) Singer \& A.H. Sm. - na pniaku; oddz. $485 \mathrm{a} ;$ IX 2018.

Laccaria amethystea (Bull.) Murrill - na ziemi; oddz. 485a, 495; VIII-IX 2018. Lactarius blennius (Fr.) Fr. - na ziemi; oddz. 487h, 496a; IX 2018.

L. necator (Bull.) Pers. - na ziemi, pod Betula; oddz. 495a; IX 2018.

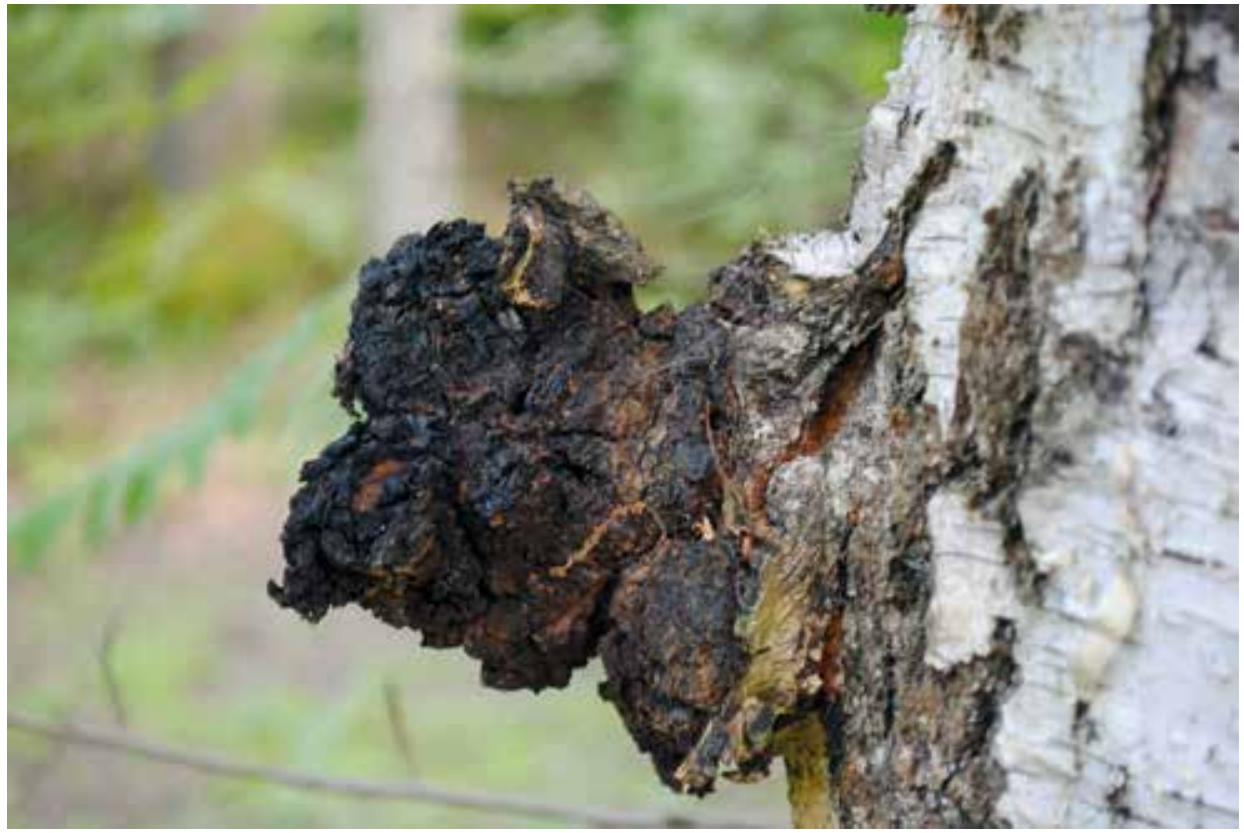

Ryc. 4. Inonotus obliquus. Fot. M. Stasińska Fig. 4. Inonotus obliquus. Phot. M. Stasińska 
L. quietus (Fr.) Fr. - na ziemi, pod Quercus; oddz. 485a; VII-IX 2018.

L. tabidus Fr. - na ziemi, pod Betula; oddz. 495b, 496; VII-IX 2018.

Laetiporus sulphureus (Bull.) Murrill - na pniu drzewa liściastego; przy drodze do Bolkowa; V-VII 2018. leg. T. Rek.

Lycoperdon nigrescens Wahlenb. - na ziemi; oddz. 487h, 488g; VII-IX 2018.

Lycoperdon perlatum Pers. - na ziemi; oddz. 485a; VII-IX 2018.

Megacollybia platyphylla (Pers.) Kotl. \& Pouzar - na zmurszałej kłodzie Betula; oddz. 486c; VII-IX 2018.

Mycena belliarum (Johnst.) P.D. Orton - na łodygach Phragmites australis; (1) SE część J. Świdwie (N 53 33' 27,8; E 14 22' 40,0); (2) przy pomoście wieży widokowej (N 53 33' 27,8; E 14 22’ 47,6); 2018 leg. et det. K. Olszanowski. E.

Mycena galericulata (Scop.) Gray - na pniaku; oddz. 485a; VII 2018.

M. galopus (Pers.) P. Kumm. - na ściółce; oddz. 485a, 488g; VII-IX 2018.

M. haematopus (Pers.) P. Kumm. var. haematopus - na murszejącej kłodzie Betula; oddz. 495; IX 2018.

M. pura (Pers.) P. Kumm. - na ściółce; oddz. 487h, 495; IX 2018.

M. sanguinolenta (Alb. \& Schwein.: Fr.) P. Kumm. - na ściółce; oddz. 502; IX 2018.

Naematelia encephala (Pers.) Fr. [=Tremella encephala Pers.] - na owocnikach Stereum sanguinolentum i gałęziach Pinus; oddz. 486c; VII 2018.

Neolentinus suffrutescens (Brot.) T.W. May \& A.E. Wood [=Lentinus lepideus (Fr.) Fr.] - na martwych kłodach Pinus; oddz. 487 k, 502c; VII-IX 2018.

Paxillus involutus (Batsch) Fr. - na ziemi; przy drodze do wieży widokowej; VII 2018.

Peniophora cinerea (Pers.) Cooke - na martwych gałązkach Betula; oddz. 485a, 486f, h, 487h, k; VII-IX 2018.

Peniophora incarnata (Pers.) P. Karst. - na martwej gałęzi; oddz. 485a; VII 2018.

P. quercina (Pers.) Cooke - na gałęzi Quercus; oddz. 485a, b, 486d, f, 507a, b; V-IX 2018.

Phaeolus schweinitzii (Fr.) Pat. - u podstawy pni Pinus; oddz. 488g, 502c; VII-IX 2018.

Phallus impudicus L. - na ziemi; oddz. 485a, b, 486c; VII-VII 2018.

Phanerochaete sanguinea (Fr.) Pouzar - na martwej gałązce; oddz. 487k; VII 2018.

Phellinus ferruginosus (Schrad.) Pat. - na gałęzi Quercus; oddz. 485a; VIII 2018.

P. punctatus (P. Karst.) Pilát - na pniu Salix; przy drodze do Bolkowa; V-IX 2018.

Phlebia tremellosa (Schrad.) Nakasone \& Burds. - na murszejącej kłodzie Betula; oddz. 496a; IX 2018. 
Piptoporus betulinus (Bull.) P. Karst. - na pniach i kłodach Betula; oddz. 485, 487h, k, 488g; V-IX 2018.

Pluteus cervinus (Schaeff.) P. Kumm. - na pniakach; oddz. 485a, d, 486c; VII-IX 2018.

Polyporus badius (Pers.) Schwein. - na martwej kłodzie Quercus; oddz. 485a; VII-IX 2018 (ryc. 6).

P. brumalis (Pers.) Fr. - na martwej gałęzi; oddz. 485a; V 2018.

P. ciliatus Fr. - na gałązkach i gałęziach Betula; oddz. 485a, d, 507a, b; VII-IX 2018.

P. tuberaster (Jacq. ex Pers.) Fr. - na martwej kłodzie; oddz. 488g (N 53 34' 745, E $14^{\circ} 20^{\prime}$ 730); VIII 2018. R.

P. squamosus (Huds.) Fr. - na drzewie liściastym; przy drodze do Bolkowa; VI 2018. leg. T. Rek.

P. varius (Pers.) Fr. - na gałęziach Fagus; oddz. 487h, 488g; VII-IX 2018.

Porodaedalea pini (Brot.) Murrill [=Phellinus pini (Brot.) A. Ames] - na żywych i martwych pniach Pinus; (1) oddz. 486c (N 53 $34^{\circ} 855$, E $14^{\circ} 21^{\circ}$

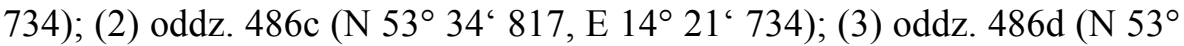
$34^{\circ} 837$, E $\left.14^{\circ} 21^{\prime} 661\right)$; (4) oddz. 486d (N 53 34' 855, E $\left.14^{\circ} 21^{\prime} 678\right)$; (5)

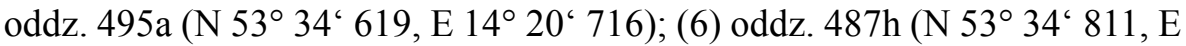

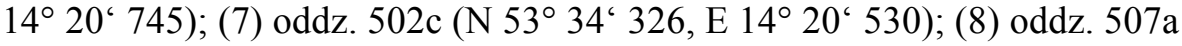

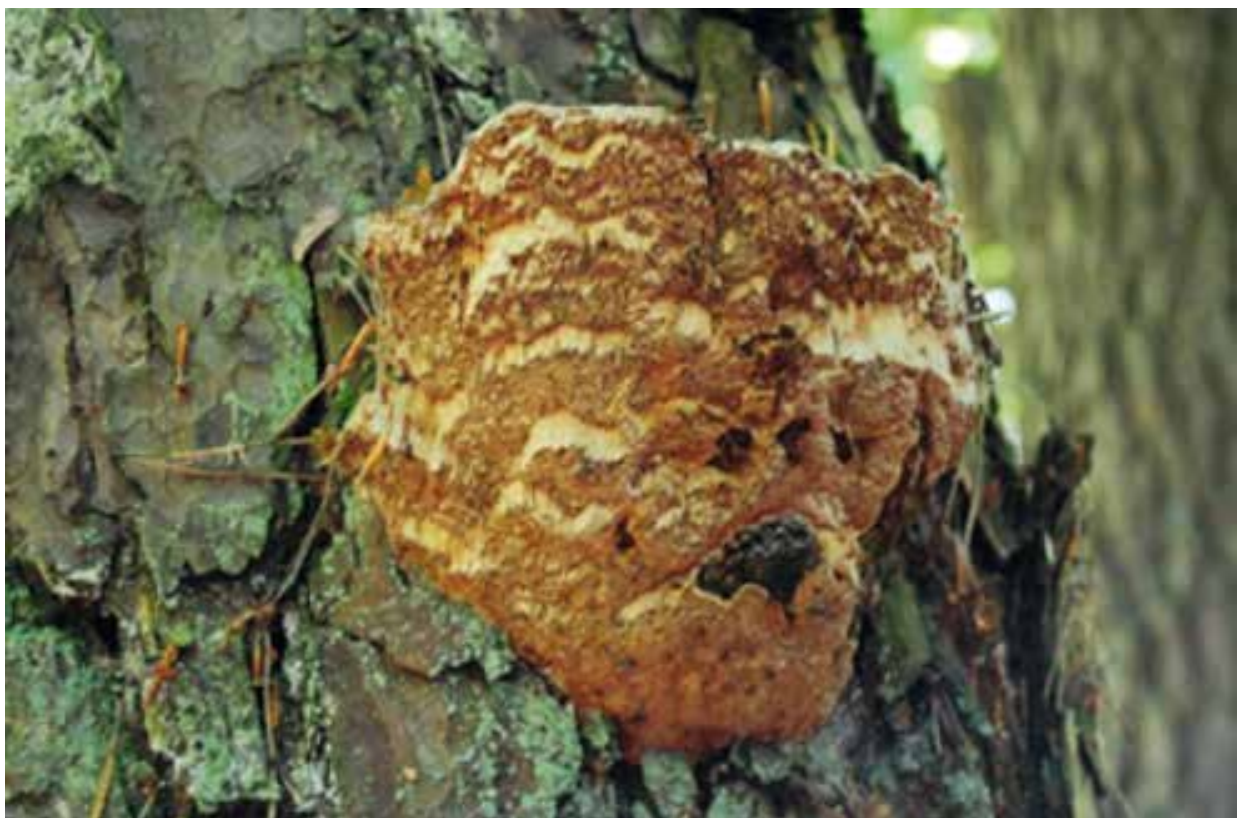

Ryc. 5. Porodaedalea pini. Fot. M. Stasińska

Fig. 5. Porodaedalea pini. Phot. M. Stasińska 


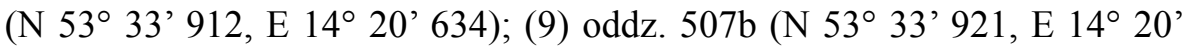
667); V-IX 2018. R (ryc. 5).

Postia caesia (Schrad.) P. Karst. - na martwej kłodzie; oddz. 486c; VII 2018. Psathyrella candolleana (Fr.) Maire - na ziemi; oddz. 485d, 494b; VII 2018.

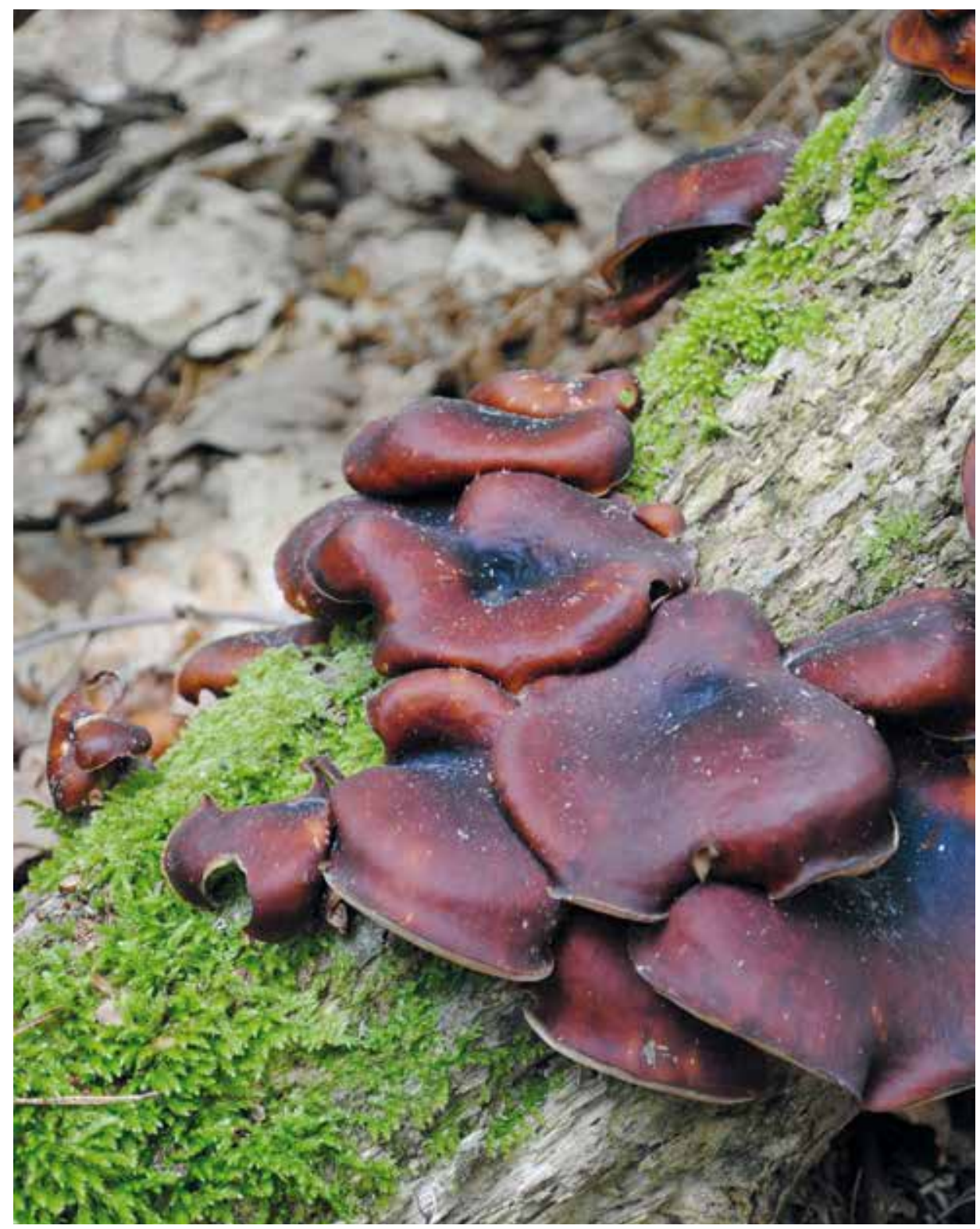

Ryc. 6. Polyporus badius. Fot. M. Stasińska Fig. 6. Polyporus badius. Phot. M. Stasińska 
Radulomyces molaris (Chaillet ex Fr.) M.P. Christ. - na martwej gałęzi; oddz. 485a, 507a, b; VII-IX 2018.

Russula cyanoxantha (Schaeff.) Fr. - na ziemi; oddz. 485a; VII-IX 2018.

R. heterophylla (Fr.) Fr. - na ziemi; oddz. 485a; VII 2018.

R. nigricans Fr. - na ziemi; oddz. 487h; IX 2018.

R. ochroleuca Pers. - na ziemi; oddz. 487h; IX 2018.

R. sororia (Fr.) Romell - na ziemi; oddz. 485a; VIII-IX 2018.

Schizophyllum commune Fr. - na gałęzi; przy drodze do Bolkowa; IX 2018.

Scleroderma citrinum Pers. - na ziemi; oddz. 485a, 486f; VIII--IX 2018.

Skeletocutis amorpha (Fr.) Kotl. \& Pouzar - na martwych pniakach i kłodach Pinus; oddz. 486c, 507a, b; VIII 2018.

Stereum hirsutum (Willd.) Gray - na murszejących gałęziach Betula i Quercus; oddz. 485a, 486c, d, 502c, 507a, b; VIII-IX 2018.

S. rugosum Pers. - na martwych pniakach; oddz. 485a, b, 486c, 487h, k; V-IX 2018.

S. sanguinolentum (Alb. \& Schwein.) Fr. - na gałęziach i kłodach Pinus; oddz. 485a, 486c, 502c, 507a, b, 512c, d; V-IX 2018.

S. subtomentosum Pouzar - na martwych gałęziach; oddz. 485a, d, 487h; VIII-IX 2018.

Stropharia aeruginosa (Curtis) Quél. - na ziemi; oddz. 485a; IX 2018.

Suillus granulatus (L.) Roussel - na ziemi; oddz. 485a; VIII 2018.

Tapinella panuoides (Fr.) E.-J. Gilbert [=Paxillus panuoides (Fr.) Fr.] - na kłodzie Pinus; oddz. 487h; IX 2018.

Thelephora terrestris Ehrh. - na ziemi i drewnie; oddz. 486c, 487h, 502c; VIII-IX 2018.

Trametes hirsuta (Wulfen) Pilát - na martwych gałęziach Betula; oddz. 486c, 487h; VIII--IX 2018.

T. versicolor (L.) Lloyd - na pniakach i gałęziach; oddz. 485a, b, 486c, d, 488g, 502c, 507a, b; VIII-IX 2018.

Tremella mesenterica Retz. - na martwej gałęzi Quercus; oddz. 507a; VIII 2018.

Trichaptum abietinum (Pers. ex J.F. Gmel.) Ryvarden - na pniakach i kłodach Pinus; oddz. 485a, b, 486c, d, f, 487h, k, 496a, 502c, 507a, b, 512b, c, d; V-IX 2018.

Trichaptum hollii (J.C. Schmidt) Kreisel [=Trichaptum fuscoviolaceus (Ehrenb.) Ryvarden] - na pniakach i kłodach Pinus; oddz. 485b, 486c, d, 487h, k, 488g, 496a; V-IX 2018.

Tylopilus felleus (Bull.) P. Karst - na ziemi; oddz. 486c, d, 502c; IX 2018.

Vuilleminia comedens (Nees) Maire - na gałęzi Quercus; oddz. 485a, 486f, 502c, 507a, 512c, d; V-IX 2018.

Xerocomellus cisalpinus (Simonini, H. Ladurner \& Peintner) Klofac - na ziemi; oddz. 485a, 486d; VIII-IX 2018. 
Xeromphalina fellea Maire \& Malençon - na ściółce iglastej; oddz. 485a; VIII 2018.

Xylodon paradoxus (Schrad.) Chevall. - na martwych gałęziach i kłodach; oddz. 485a, 486c, d, f, 487h, k, 488g, 496a, 507a, b; VIII-IX 2018.

\section{PODSUMOWANIE}

Na terenie rezerwatu przyrody „Świdwie” w ciągu niespełna roku i przy niekorzystnych warunkach klimatycznych stwierdzono łącznie 117 taksonów grzybów, w tym pięć znajdujących się na czerwonej liście grzybów wielkoowocnikowych w Polsce. Większość z odnotowanych tam gatunków grzybów makroskopijnych charakteryzuje się dość szeroką skalą ekologiczną. Jednak znaczna różnorodność macromycetes rezerwatu, jak i udział taksonów zagrożonych i chronionych wskazują na dużą wartość przyrodniczą tego obiektu, nie tylko pod względem faunistycznym. $Z$ drugiej strony biologia tej grupy organizmów i wynikająca z niej konieczność prowadzenia przynajmniej kilkuletnich obserwacji powodują, że uzyskane wyniki stanowią jedynie kolejny przyczynek do znajomości mycobioty rezerwatu. Liczba występujących tam taksonów grzybów jest zapewne znacznie większa, co na pewno znajdzie odzwierciedlenie w dalszych badaniach.

\section{LITERATURA}

Bosiacka B., Więcław H. (2013/2014): Biota grzybów wielkoowocnikowych rezerwatu Świdwie. [W:] Jasnowska J. (red.). Rezerwat przyrody Jezioro Świdwie 1963--2013. Środowisko Pomorza Zachodniego, Ochrona i Zarządzanie środowiskiem przyrodniczym: 45-46. I wydanie specjalne z okazji 50-lecia rezerwatu „Świdwie”. RDOŚ. Szczecin.

Bosiacka B., Więcław H., Wilhelm M. (2013/2014): Szata roślinna rezerwatu Świdwie. [W:] Jasnowska J. (red.). Rezerwat przyrody Jezioro Świdwie 1963-2013. Środowisko Pomorza Zachodniego, Ochrona i Zarządzanie środowiskiem przyrodniczym: 40-44. I wydanie specjalne z okazji 50-lecia rezerwatu „Świdwie”. RDOŚ. Szczecin.

Friedrich S. (2006): Threatened and protected macromycetes in the Wkrzańska Forest. Acta Mycol., 41(2): 229-240.

Index Fungorum. http://www.indexfungorum.org (dostęp: 2.03.2019).

Matuszkiewicz W. (2001): Przewodnik do oznaczania zbiorowisk roślinnych Polski. Ss. 537. Ser. Vademecum Geobot., 3. Wyd. Nauk. PWN. Warszawa.

Mirek Z., Piękoś-Mirkowa H., Zając A., Zając M. (2002): Flowering Plants and Pteridophytes of Poland. A checklist. Ss. 442. Ser. Biodiversity of Poland, 1. W. Szafer Inst. of Bot., Pol. Acad. of Sci. Kraków.

Robert V., Stegehuis G., Stalpers J. (2005): The MycoBank engine and related databases. http:// www.mycobank.org (dostęp: 2.03.2019).

Rozporządzenie Ministra Środowiska z dnia 9 października 2014 r. w sprawie ochrony gatunkowej grzybów. Dz.U. z dn. 16 października 2014 r., poz. 1408. 
Wojewoda W. (2003): Checklist of Polish larger Basidiomycetes. Ss. 812. W. Szafer Inst. of Bot., Pol. Acad. of Sci. Kraków.

Wojewoda W., Ławrynowicz M. (2006): Red list of macrofungi in Poland. [W:] Mirek Z., Zarzycki K., Wojewoda W., Szeląg Z. (red.). Red list of plants and fungi in Poland: 53-70. W. Szafer Inst. of Bot., Pol. Acad. of Sci. Kraków.

Zarządzenie Ministra Leśnictwa i Przemysłu Drzewnego z dnia 14 stycznia 1963 r. w sprawie uznania za rezerwat przyrody. Monitor Polski nr 14, poz. 82.

\section{CONTRIBUTION TO THE STUDY OF MACROMYCETES IN "ŚWIDWIE" NATURE RESERVE (NW POLAND)}

\section{Summary}

Mycological studies were conducted in "Świdwie" nature reserve located on the southern edge of Wkrzańska Forest and about $23 \mathrm{~km}$ from the center of Szczecin, by means of the route method, from May to September 2018. In total, 117 macromycete species were recorded: 15 Ascomycota and 102 Basidiomycota. Five of those species are included in the Polish red list of macrofungi (Wojewoda, Ławrynowicz 2006), compiled according to their endangerment categories. One species: Mycena belliarum belongs to category E (endangered); four species: Inonotus obliquus, Fistulina hepatica, Polyporus tuberaster and Porodaedalea pini are R (rare). Two of the endangered species are under partial protection, namely Fistulina hepatica and Inonotus obliquus.

The considerable diversity of the fungi in the reserve, as well as the share of the endangered and protected taxa, indicate the reserve's high nature value, not only in terms of the fauna. 